\title{
THE DEFORMATION ANALYSIS AND MESO OBSERVATION TESTS OF PILE SIDE FINE SAND UNDER LATERAL LOADING
}

\author{
Liu Wenbai ${ }^{1}$, Deng Yibing ${ }^{2}$, Guo Rong ${ }^{3}$
}

\begin{abstract}
The pile side soil deformation analysis and meso-observation were conducted for revealing the meso-mechanism of lateral bearing pile with practical significance. Lateral cyclic load tests were carried out on full model and semispatial mode single piles embedded in fine sand to study the behaviour of pile side soil. Through the digital photography and microscopic meso-observation images on the semispatial model test, digital photography for the deformation of soil analysis, and microscopic meso-observation images for the meso-structure analysis, carry out the works of soil mesomechanical properties and its associated research, test method of macro and meso-analysis was proposed. Through non-marking points digital photogrammetry of deformation measurement system, the biggest shearing strain, volumetric strain and displacement vector distribution of pile the surrounding fine sand of the laterally loading on experiments of semispatial model was analysed, depends on this determination the shearing failure area and mesoobservation point. The applied MiVnt image analysis system has processed the meso-observation images of soil structure, has sum up and analysed the change of meso-parameters, numbers of particles, total area of particles, voil ratio e, voil ratio increment, major axis mean of particles, minor axis mean of particles, eccentricity mean of particles, particle size, particle direction. This is an effective method of analysis, through deformation analysis and mesostructure analysis of soil structure on the semispatial model test, studing the macro-and meso-mechanical properties and its correlation.
\end{abstract}

Keywords: pile side fine sand; laterally loading; deformation; meso-mechanics; surface of rupture

\section{INTRODUCTION}

In the field of coastal engineering, Pile foundations are extensively used in supporting several structures such as breakwater, wharf, bridge(Mostafa et al. 2006 ). In many cases, piles are subjected to significant lateral loads. The environment prevalent in the ocean necessitates the piles to be designed for cyclic wave loading(Rao et al. 1993; Sumer et al. 2007).

Analysis of pile foundation and the stress and deformation of pile side soil are the key points of theoretical study on pile foundation under lateral loading. Most studies were focused on the force and deformation of pile body, while little attention on pile side soil in the previous research on the lateral loaded piles. In fact, the behavior of pile depend on the deformation and failure characteristics of pile side soil. The pile side soil deformation analysis and meso-observation were conducted for revealing the meso-mechanism of lateral bearing pile with practical significance.

In this investigation, the pile side soil deformation analysis and meso-observation were conducted for revealing the meso-mechanism of lateral bearing pile through model tests.

\section{MODEL EXPERIMENT}

\section{Setup of Experiment}

Lateral cyclic load tests were carried out on full model and semispatial model single piles embedded in fine sand to study the behaviour of pile side soil. The employed testing apparatus is shown in Fig. 1. To study the deformation of soil around pile development, a semispatial test was conducted (Dickin and Leung 1985; Sakai and Tanaka 2007). The test container serves as a soil bin, which was fabricated of steel members $80 \mathrm{~cm}$ long, $80 \mathrm{~cm}$ wide, and $100 \mathrm{~cm}$ high. The size of box container was designed large enough to minimize the influence of the box boundaries. One sidewall was made of 1-cm-thick glass plate. Model piles with relative length of 4.2 were used as flexible pile. The properties of model pile are presented in Table 1.

\footnotetext{
${ }^{1}$ Department of Port Waterway Engineering, Shanghai Maritime University, 1550 Haigang Av., Shanghai , 201306, PR China

${ }^{2}$ Department of Port Waterway Engineering, Shanghai Maritime University, 1550 Haigang Av., Shanghai , 201306, PR China

${ }^{3}$ Department of Port Waterway Engineering, Shanghai Maritime University, 1550 Haigang Av., Shanghai , 201306, PR China
} 

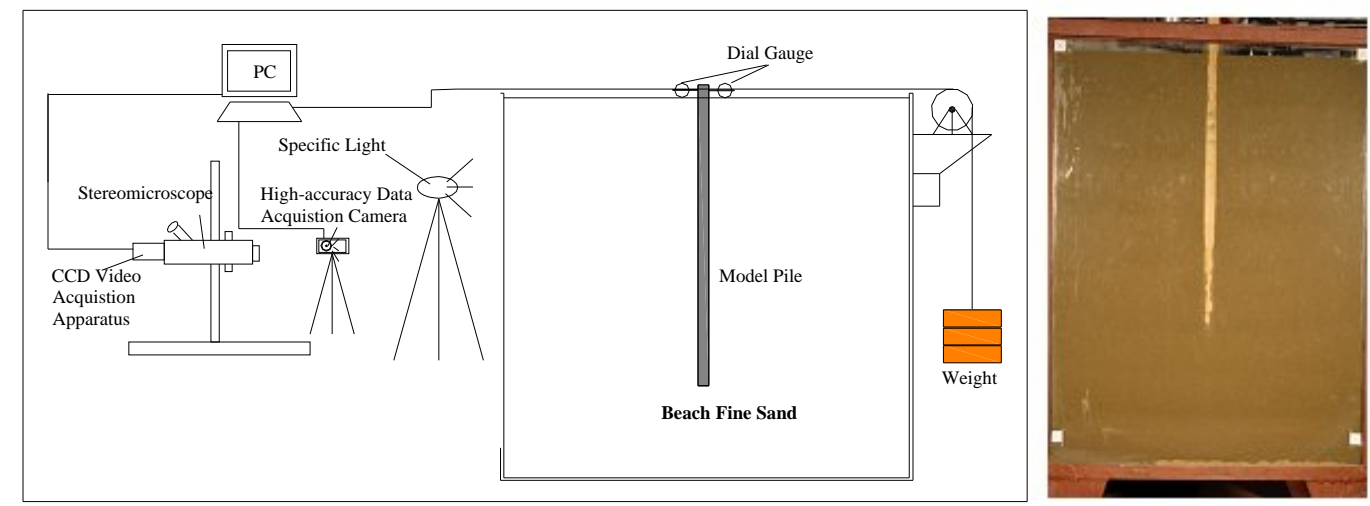

Figure 1. Schematic diagram of experiment setup

\begin{tabular}{|c|c|c|c|c|c|c|c|}
\hline $\begin{array}{l}\text { Pile } \\
\text { length } \\
\mathrm{L} / \mathrm{m}\end{array}$ & $\begin{array}{l}\text { Section } \\
/ \mathrm{m} \times \mathrm{m}\end{array}$ & $\begin{array}{c}\text { Embedded } \\
\text { Depth/m }\end{array}$ & $\begin{array}{c}\text { Distance between load } \\
\text { point and soil } \\
\text { surface } / \mathrm{m}\end{array}$ & E/Mpa & $\begin{array}{l}\text { Moment of } \\
\text { Inertia } 1 / \mathrm{m}^{4}\end{array}$ & $\mathrm{D} / \mathrm{L}$ & $\begin{array}{c}\text { Relative length } \\
Z_{t}\end{array}$ \\
\hline 0.65 & $0.02 \times 0.02$ & 0.55 & 0.01 & $1 \times 10^{4}$ & $1.33 \times 10^{-8}$ & 0.03 & 4.2 \\
\hline
\end{tabular}

\section{Sample Preparation}

The tests were conducted in beach fine sand. The macro-properties of soil materials are given in Table 2. The model pile was placed and located in the center of the steel container box. The sand was rained through a raining device with one sieve. A depth of sand mass with uniform density was formed by keeping the height of fall of sand and the intensity of deposition. After sample preparation $24 \mathrm{~h}$, the test was carried out.

\begin{tabular}{|c|c|c|c|c|c|c|c|c|c|c|c|c|c|}
\hline \multirow{2}{*}{$\begin{array}{l}\text { W } \\
\%\end{array}$} & \multirow{2}{*}{$\begin{array}{c}\rho_{s} \\
\mathrm{~g} / \mathrm{cm}^{3}\end{array}$} & \multirow[t]{2}{*}{$\mathrm{G}_{\mathrm{s}}$} & \multirow[t]{2}{*}{ e } & \multicolumn{6}{|c|}{ Particle gradation $/ \mathrm{mm}$} & \multirow{2}{*}{$\begin{array}{r}\mathrm{C}_{\mathrm{q}} / \\
\mathrm{kPa}\end{array}$} & \multirow{2}{*}{$\phi_{q}{ }^{\prime}$} & \multirow{2}{*}{$\begin{array}{c}\mathrm{a}_{\mathrm{v}}{ }^{\prime} \\
\mathrm{Mpa}^{-1}\end{array}$} & \multirow{2}{*}{$\begin{array}{r}E_{s} / \\
\mathrm{Mpa}\end{array}$} \\
\hline & & & & $\begin{array}{l}> \\
1\end{array}$ & $\begin{array}{c}1 \\
\sim 0.5\end{array}$ & $\begin{array}{c}0.5 \\
\sim 0.25\end{array}$ & $\begin{array}{l}0.25 \\
\sim 0.1\end{array}$ & $\begin{array}{c}0.1 \\
\sim 0.075\end{array}$ & $\begin{array}{c}<< \\
0.075\end{array}$ & & & & \\
\hline 5.45 & 1.81 & 2.65 & 1.57 & $0.01 \%$ & $0.12 \%$ & $0.53 \%$ & $96.1 \%$ & $\begin{array}{c}2.51 \\
\%\end{array}$ & $0.73 \%$ & 0 & 41 & 0.21 & 12.1 \\
\hline
\end{tabular}

\section{Test Procedure}

Lateral cyclic load tests were conducted on piles by rope and pulley arrangement up to failure and loaddeflection curves were obtained. The lateral load was maintained by one way multi-cycle , and onefifteenth of static lateral capacity was applied as the load differential. Each level of loading, loading and unloading cycle 5 times, until the failure load.

Two kinds of digital cameras were used in the model test for the macro and meso scale. The digital camera was located in front of the container box to continuously take pictures for analysis of the deformation of soil, with two specific lights. The field of displacement and strain of soil were obtained by employing digital photography and image analysis together with non-target method to analyzing the digital photos. The stereomicroscope closed to the glass wall of the container box to observe the variations of microcosmic parameters of soil.

\section{RESULTS AND DISCUSSION}

\section{Analysis of load-deflection curves}

The load-deflection curve is illustrated in Fig. 2. The $5^{\text {th }}$ level of loading reached the critical load of pile and the $11^{\text {th }}$ level of loading reached the ultimate load of pile. The load-defection relationship experienced 3 stages. First stage, the cyclic load levels less than the critical load the residual deflection is very small and increased slowly with number of cycles. For cyclic load levels greater than the critical 
load less than the ultimate load the deflections are observed to increase with number of cycles and cyclic load level and stabilise after a certain number of cycles. For cyclic load levels greater than the ultimate load, the deflections are observed to increase enormously with number of cycles. The soil crack obviously around pile. Passive soil surface significantly uplift and failure.
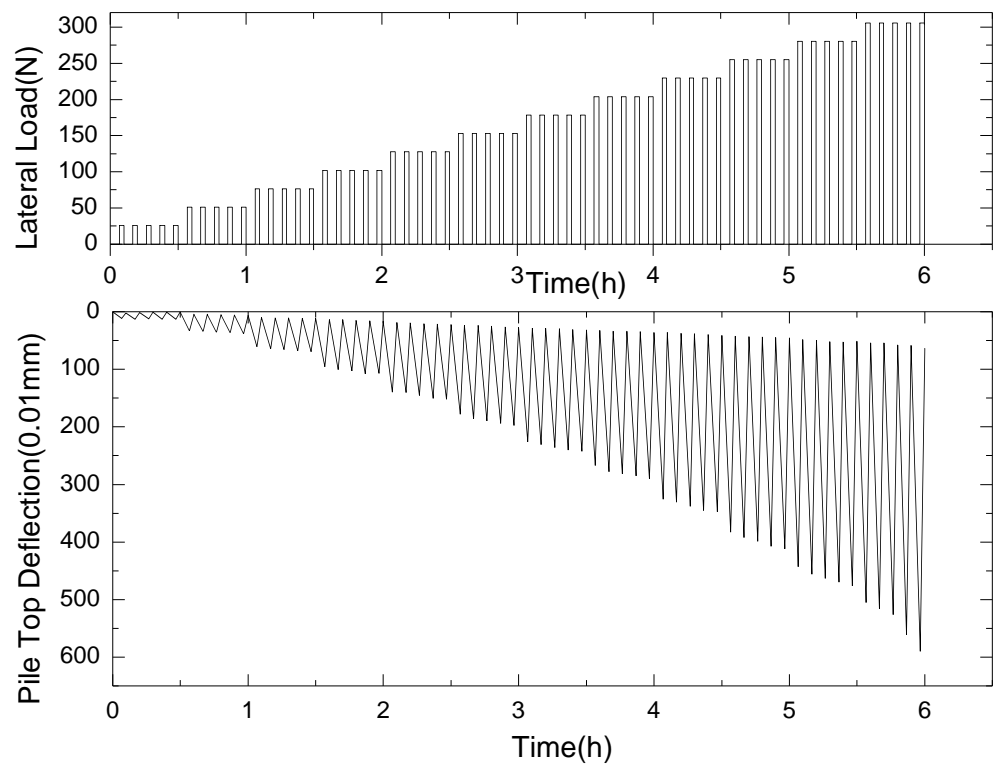

Figure 2. Lateral load-time-pile displacement curve

\section{Deformation Analysis}

The macro-scale deformation of the soil were analyzed by using digital photography and image analysis together with non-target method (Yuanhai Li 2006). Due to the unsymmetrical lateral deformation of soil, the widths of active soil region and passive soil region were $11 \mathrm{~cm}$ and $24 \mathrm{~cm}$, respectively. The dimension of $34 \mathrm{~cm}$ in width by $24 \mathrm{~cm}$ in height was selected as the image analysis region, which included the whole soil deformation region. The region of image analysis was set as illustrated in Fig. 3.

The soil displacement field at each stage was obtained by processing the continuous digital photos. Fig. 4 show the soil displacement propagation at different load levels including loading and unloading in the semispatial test. 5-5 is used to express cycles 5 at $5^{\text {th }}$ level of lateral load. It was observed that the depth of deformation was approximately 0.21 embedded depth at the critical load, 0.32 embedded depth at the ultimate load and 0.37 pile embedded depth at the failure load respectively. For cyclic load levels up to the critical load $\left(5^{\text {th }}\right.$ level load), a triangular deformation zone distributed in the active region, and the affected zone developed down along pile. The deformation zone distributed in the passive surface region as horizontal stripple, extent outward. The two deformation zones composed the lateral resistance. For cyclic load levels up to the ultimate load $\left(11^{\text {th }}\right.$ level load), the deformation zone mainly distributed in the passive region as triangle, the affect zone stabilise in soil surface zone and developed down along pile. The passive soil support the main lateral resistance. When cyclic load levels up to the failure load $\left(12^{\text {th }}\right.$ level load), the total affect zone stabilise, the side soil failure. The sliding surface developed down from the surface of soil into the depth of 0.37 pile embedded depth in half inverted cone shape within the passive soil region. The inclination angle of the sliding surface to the surface of soil was approximately $60^{\circ}$. In the active soil region, the shear band developed down in thin strip, the width of deformation was approximately 0.5 pile diameter, the depth of deformation was consistent with the depth of pile deformation. 


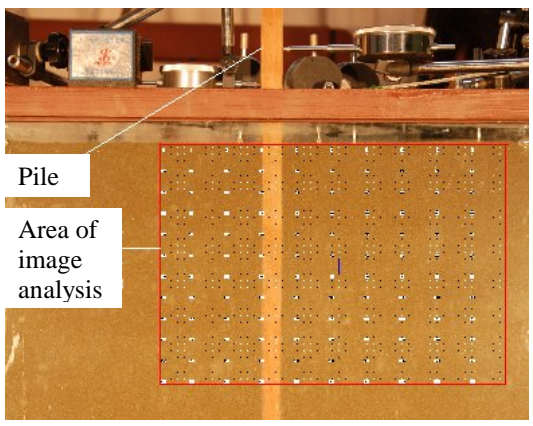

Figure 3. The region of image analysis
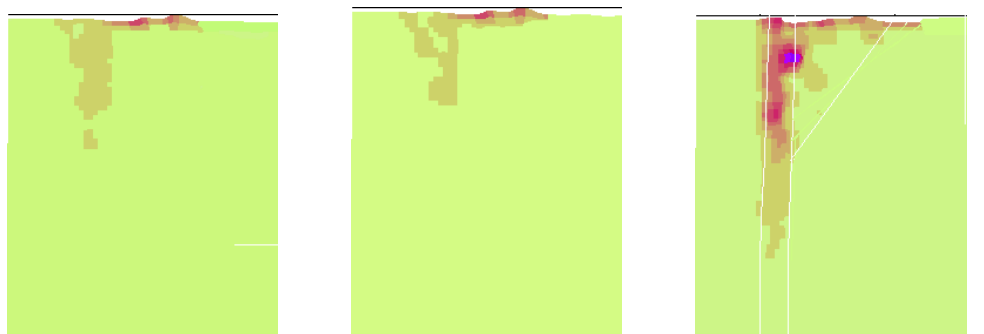

a) loading at 5-5 level load b) unloading at 5-5 level load c) loading at 11-5 level load
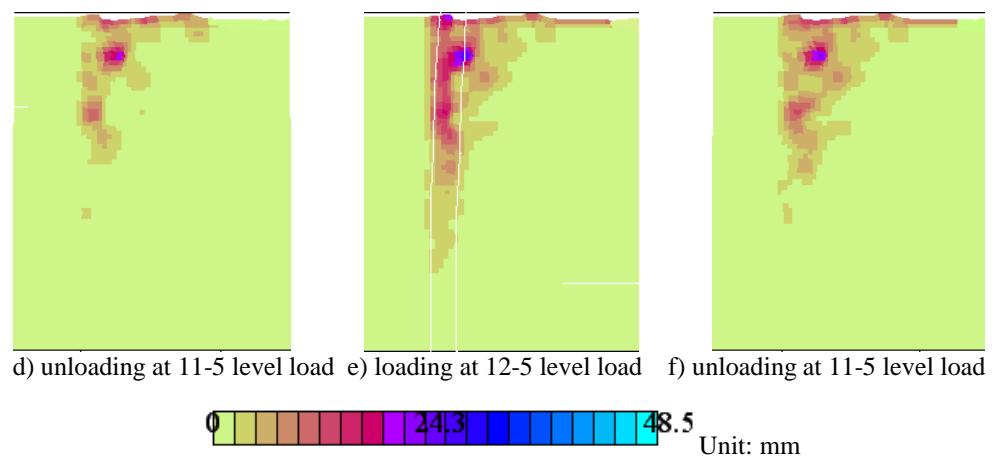

Figure 4. Image of soil displacement

\section{Meso-observation of Pile Side Sand}

Based on the analysis of deformation field and the observation of failure surface, the soil mesoobservation regions were designated for the analysis of meso-structural propagation as follow, the pile and soil interface — 1 \# point, within the plastic region_ $-2 \#$ point and plastic region edge -3 \# point(shown in Fig .5). The stereomicroscope was applied to take the particle-scale pictures of the three points during testing. The parameters of soil meso-structure were acquired by employing the Mivnt software (Zhou Jian 2006) to process the particle-scale picture as shown in Fig 6. 


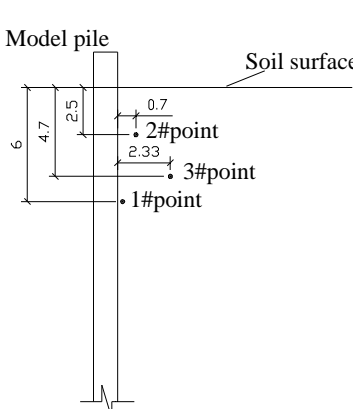

Figure 5. Meso-observation points

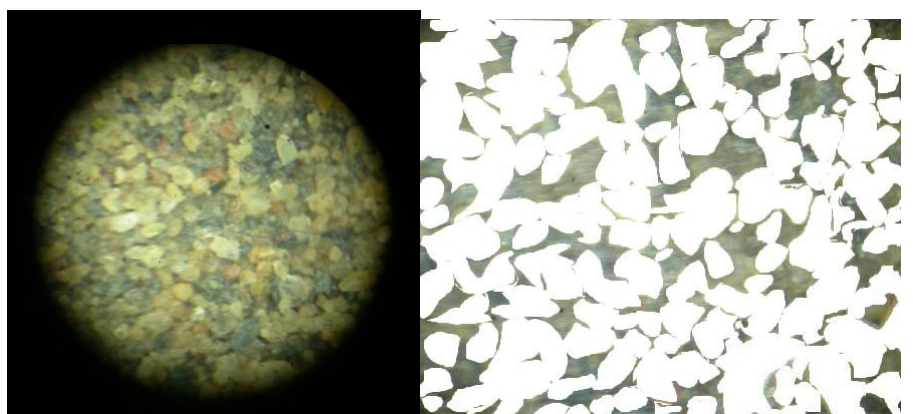

a) Original image

Figure 6. Soil meso-structure of 2\# observation point on 11-5 level load

Quantitative meso-structural analysis of sand was conducted by the lateral cyclic loading model test on single pile. Table 3 enumerates the data of meso-structural on the $1 \#$ point at different load levels. The information illustrated the responding between particle meso-scale and macro mechanics.

The shear strength of cohesionless soil under low stress condition composed of three components, namely, the strength exerted by friction of particle sliding, the strength produced by the energy required for arrangement and direction, and the strength of shear dilatancy. In the initial stage of test, the particle sliding friction played a mainly role in resistance against the lateral load, which resulted in the small deflection of soil and pile. With the increasing of load and cycle number, the deformation of soil and pile increased. The relative displacement between particle and the area of pore increased, which reflected shear dilatancy in macro scale. The sliding friction decreased in the proportion of the the shear strength while the component of the shear dilatancy in the strength increased. With the load further increasing, the reduced sliding friction resistance contributed to the arrangement and direction of particles which resulted in increasing the shear strength due to absorbing energy. The growth rate of soil displacement slowed down accordingly.

Among the three observation point, the particles in the 1\# observation point at interface of pile-soil surfer the most influence from the load and displacement of pile. The porosity and particle area varied significantly with the change between loading and unloading. The number of particles within the observation region reduced due to shear dilation during loading, while the number increased due to shear contraction during unloading. The particles of $1 \#$ point showed the most obvious direction under failure load condition. The particles within the $2 \#$ observation point occurred mainly in the horizontal direction under the stress dispersion at side pile. The displacement and porosity variation of particle within 2\# point were smaller than them within 1\# point. The direction and the rearrangement presented by particles within $2 \#$ point were weaker than them within 1\# point as result of the less horizontal resistance produced by the shear dilation. The major axis direction of particle in $3 \#$ observation point at the edge of plastic zone distributed dispersive by the effect of the shear band. In 3\# point, the particle displacement and porosity area were the smallest, with more obvious shear contraction. The force acted on the $2 \#$ point and $3 \#$ point were transferred gradually by each sand particle, therefore, the cycle of loading and unloading impacted on the two point with hysteresis.

The eccentricity was defined as the ratio of long axis and short axis of particles to illustrate the feature of particle shape in meso-scale. The eccentricity of $1 \#$ point was larger than them of $2 \#$ point and $3 \#$ point, the eccentricity of $2 \#$ point and $3 \#$ point was 0.59 and 0.6 , respectively. When the load reaching the ultimate load, the eccentricity changed significantly, the eccentricity of $1 \#$ point reduced to the minimum of 0.5 , the eccentricity of $2 \#$ point reduced from 0.6 at $1^{\text {th }}$ cycle to 0.53 at $5^{\text {th }}$ cycle, the eccentricity of $2 \#$ point changed gradually, it reduced to the minimum of 0.53 under loading of $5^{\text {th }}$ cycle and rebounded subsequently after unloading of $5^{\text {th }}$ cycle because the significant variation of particle weakened the constraint between particles and made particle rotation. Table 4 shown the parameter summary of soil meso-structure at the three observation point under the failure load. 1\# point's ratio of area particles (particle area / observation area size) was the smallest while 3\# point's was the most. The proportion of the obtuse angle in the particle direction was $80-90 \%$. The porosity area ratio at 1 \# point was the maximum, the particles direction was the most significant when load reached failure load. The porosity area ratio at 2 \# point was smaller, particle direction was relatively 
significant; 3 \# points at failure sliding surface, soil particle displacement was the smallest, the particle direction was not significant.

\begin{tabular}{|c|c|c|c|c|}
\hline Load level & Number of particle & $\begin{array}{l}\text { Total area of particle } \\
/ \mathrm{um}^{2}\end{array}$ & $\begin{array}{l}\text { Eccentricity mean of } \\
\text { particles }\end{array}$ & $\begin{array}{l}\text { Major axis mean of } \\
\text { particles /um }\end{array}$ \\
\hline 0 & 71 & 6653.9432 & $4.965 e-001$ & $1.542 \mathrm{e}+001$ \\
\hline 5-1loading & 86 & 6894.8895 & $5.101 \mathrm{e}-001$ & $1.411 \mathrm{e}+001$ \\
\hline 5-1unloading & 97 & 6917.3501 & $5.210 \mathrm{e}-001$ & $1.259 \mathrm{e}+001$ \\
\hline 5-5loading & 93 & 7022.9022 & $5.415 \mathrm{e}-001$ & $1.361 \mathrm{e}+001$ \\
\hline 5-5unloading & 93 & 7051.4195 & $5.493 e-001$ & $1.306 \mathrm{e}+001$ \\
\hline 11-1loading & 83 & 6250.1577 & $4.985 \mathrm{e}-001$ & $1.359 e+001$ \\
\hline 11-1unloading & 85 & 6664.9211 & $5.077 \mathrm{e}-001$ & $1.377 \mathrm{e}+001$ \\
\hline 11-5loading & 73 & 6153.1861 & $5.046 \mathrm{e}-001$ & $1.431 \mathrm{e}+001$ \\
\hline 11-5unloading & 79 & 6638.1703 & $5.166 \mathrm{e}-001$ & $1.382 \mathrm{e}+001$ \\
\hline 12-1loading & 65 & 6223.5962 & $5.367 \mathrm{e}-001$ & $1.474 \mathrm{e}+001$ \\
\hline 12-1unloading & 92 & 7009.0221 & $5.484 \mathrm{e}-001$ & $1.271 \mathrm{e}+001$ \\
\hline 12-5loading & 84 & 7120.6309 & $5.248 \mathrm{e}-001$ & $1.460 \mathrm{e}+001$ \\
\hline 12-5unloading & 74 & 6746.6246 & $5.180 \mathrm{e}-001$ & $1.487 e+001$ \\
\hline
\end{tabular}

\begin{tabular}{|c|c|c|c|c|c|c|c|c|c|c|}
\hline \multirow{2}{*}{$\begin{array}{c}\text { Analysis } \\
\text { region }\end{array}$} & \multicolumn{2}{|c|}{ Porosity ratio } & \multicolumn{3}{|c|}{ particle meso-parameters } & \multicolumn{4}{|c|}{$\begin{array}{l}\text { particle direction } \\
\text { distribution/\% }\end{array}$} & \multirow[b]{2}{*}{$\begin{array}{l}\text { Load } \\
\text { /N }\end{array}$} \\
\hline & e & $\Delta \mathrm{e}_{\mathrm{i}}$ & $\begin{array}{c}\text { Ratio of } \\
\text { area } \\
\text { particles/\% }\end{array}$ & $\begin{array}{l}\text { major axis } \\
\text { mean of } \\
\text { particles/um }\end{array}$ & $\begin{array}{l}\text { Eccentricity } \\
\text { mean of } \\
\text { particles/um }\end{array}$ & $\begin{array}{l}0^{\circ}- \\
90^{\circ}\end{array}$ & $\begin{array}{l}90^{\circ}- \\
120^{\circ}\end{array}$ & $\begin{array}{l}120^{\circ}- \\
150^{\circ}\end{array}$ & $\begin{array}{l}150^{\circ}- \\
180^{\circ}\end{array}$ & \\
\hline 1\# & 0.366 & 0.071 & 0.634 & $1.460 \mathrm{e}+001$ & $5.248 \mathrm{e}-001$ & 11.9 & 19.0 & 42.8 & 26.2 & 306 \\
\hline 2\# & 0.249 & 0.059 & 0.750 & $1.290 \mathrm{e}+001$ & $5.677 \mathrm{e}-001$ & 13.6 & 15.9 & 40.3 & 30.1 & 280 \\
\hline 3\# & 0.268 & -0.04 & 0.732 & $1.252 e+001$ & $5.696 \mathrm{e}-001$ & 20.1 & 19.4 & 30.9 & 29.5 & 280 \\
\hline
\end{tabular}

\section{CONCLUSION}

The triangular deformation zone of active soil and horizontal stripple deformation zone of passive soil compose the lateral resistance when pile subjected to lateral critical load, while The triangular deformation zone of passive soil along pile compose the lateral resistance when pile subjected to lateral ultimate load and failure load.

The variation of meso-structure of pile side soil reflected the interaction of pile-soil by the pile displacement. The regularity of variation of meso-structure parameters revealed the direct relevance between the micro-and macro-mechanical parameters. The correlation between the micro-and macroparameters need to further study

\section{REFERENCES}

Dickin, E. A., and Leung, F. 1985. Evaluation of design methods for vertical anchor plates. J. Geotech. Engrg., 111(4), 500-520.

Mostafaa,Y.E., Naggar, E., and Hesham, M. 2006. Effect of seabed instability on fixed offshore platforms, Soil Dynamics and Earthquake Engineering, 26, 1127-1142.

Sumer, B. M., Hatipoglu, F., and Fredsøe, J. 2007. Wave Scour around a Pile in Sand, Medium Dense, and Dense Silt, Journal of Waterway, Port, Coastal, and Ocean Engineering, 133(1), 14-27

Rao, S.N., and Rao, K.M. 1993. Behaviour of rigid piles in marine clays under lateral cyclic loading, Ocean Engineering, 20(3), 281-293.

Sakai, T., and Tanaka, T. 2007. Experimental and Numerical Study of Uplift Behavior of Shallow Circular Anchor in Two-Layered Sand, Journal of Geotechnical and Geoenvironmental Engineering, 133(4), 469-477 
Yuanhai Li(2006). Development and Application of Digital Photogrammetry Software Package for Geotechnical Engineering. Chinese Journal of Rock Mechanics and Engineering, 25 (S2), 38593866.

Zhou, J., Yu, R. C., and Jia, M. C. 2006. Measurement of microstructure parameters for granular soil model using digital image technology, Chinese Journal of Geotechnical Engineering, 28(12):20482052 . 